\title{
The association of the CYPIAI Ile462Val polymorphism with head and neck cancer risk: evidence based on a cumulative meta-analysis
}

This article was published in the following Dove Press journal:

OncoTargets and Therapy

17 May 2016

Number of times this article has been viewed

\author{
Yadong Wang ${ }^{1,2, *}$ \\ Haiyan Yang ${ }^{3, *}$ \\ Guangcai Duan² \\ Haiyu Wang' \\ 'Department of Toxicology, Henan \\ Center for Disease Control and \\ Prevention, Zhengzhou, ${ }^{2}$ Henan \\ Collaborative Innovation Center of \\ Molecular Diagnosis and Laboratory \\ Medicine, Xinxiang Medical \\ University, Xinxiang, ${ }^{3}$ Department of \\ Epidemiology, School of Public Health, \\ Zhengzhou University, Zhengzhou, \\ People's Republic of China \\ *These authors contributed equally \\ to this work
}

Correspondence: Yadong Wang Department of Toxicology, Henan Center for Disease Control and Prevention, No 105 of South Nongye Road, Zhengzhou 450016, People's Republic of China

Tel/fax +86 37I 68089043

Email wangyd76@।63.com
Objective: The aim of this study was to address the association between the Ile $462 \mathrm{Val}$ polymorphism in the gene encoding cytochrome P450 1A1 (CYP1A1) and the risk of head and neck cancer (HNC).

Materials and methods: The Medline/PubMed, EMBASE, and Web of Science databases were searched. The strength of the association was evaluated by calculating the odds ratio (OR) with a $95 \%$ confidence interval (CI).

Results: Overall, we observed an increased risk of HNC in patients with the Ile/Val+Val/ Val genotype compared to those with the Ile/Ile genotype among the 6,367 cases and 6,395 controls evaluated in the 34 eligible studies, with a pooled OR of 1.284 (95\% CI: 1.119-1.473). In addition, we observed an increased risk of HNC in patients with the Ile/ $\mathrm{Val}+\mathrm{Val} / \mathrm{Val}$ genotype compared to those with the Ile/Ile genotype in the subgroup analyses $(\mathrm{OR}=1.362,95 \% \mathrm{CI}$ : $1.102-1.685$ for laryngeal cancer; OR $=1.519,95 \% \mathrm{CI}: 1.253-1.843$ for pharyngeal cancer; OR $=1.371,95 \% \mathrm{CI}$ : $1.111-1.693$ for Asians; and OR $=1.329,95 \%$ CI: 1.138-1.551 for patients in studies using hospital-based controls).

Conclusion: This cumulative meta-analysis suggests that the CYP1A1 Ile462Val polymorphism might contribute to the risk of $\mathrm{HNC}$, particularly for pharyngeal cancer and laryngeal cancer.

Keywords: $C Y P 1 A 1$, polymorphism, head and neck cancer, oral cancer, laryngeal cancer, pharyngeal cancer, risk

\section{Introduction}

Head and neck cancer (HNC) is a broad term that encompasses epithelial malignancies that arise in the paranasal sinuses, nasal cavity, oral cavity, pharynx, and larynx. $\mathrm{HNC}$ is the sixth most common type of cancer, representing $\sim 6 \%$ of all cancer cases and accounting for an estimated 650,000 new cases and 350,000 cancer deaths worldwide each year. ${ }^{1}$ Tobacco smoking and alcohol intake are considered the major risk factors for $\mathrm{HNC}{ }^{2}{ }^{2}$ however, only a small proportion of smokers and alcohol users develop HNC in their lifetime, suggesting that individual susceptibility might also be a significant factor in disease etiology. The Cancer Genome Atlas profiled 279 head and neck squamous cell carcinomas and provides a comprehensive landscape of the somatic genomic aberrations associated with HNC. ${ }^{3}$

The gene encoding cytochrome P450 1A1 (CYP1A1) maps to chromosome 15 and encodes an aryl hydrocarbon hydrolase that plays a role in the metabolism of the carcinogenic polycyclic aromatic hydrocarbons that are present in tobacco smoke. Previous studies have demonstrated that an amino acid substitution from isoleucine to valine in codon 462 (rs1048943, A4889G) in exon 7 of CYP1A1 enhances the 
catalytic activity of the cytochrome P450 1A1 protein ${ }^{4,5}$ and influences the risk of several cancers. ${ }^{6-10}$ To date, a number of epidemiological studies that have explored the association between the CYP1A1 Ile462Val polymorphism and the risk of HNC have been reported. ${ }^{11-44}$ However, the results of these studies have been conflicting rather than conclusive. Thus, we conducted a cumulative meta-analysis of eligible published studies to further evaluate the association between the Ile462Val polymorphism and HNC risk.

\section{Materials and methods}

\section{Literature source and analytical methods}

We searched the Medline/PubMed, EMBASE, and Web of Science databases for articles published until December 31,2015 , using various combinations of the following keywords in the search parameters: HNC, oral cancer, oral cavity cancer, pharyngeal cancer, laryngeal cancer, $C Y P 1 A 1$, cytochrome P450 1A1, rs1048943, polymorphism, and variant. In addition, we manually searched the reference list of relevant publications to identify additional studies.

The selection criteria of the eligible publications included the following: 1) the study that evaluated the CYP1A1 Ile462Val polymorphism and the risk of $\mathrm{HNC}$; 2) the publication that reported a case-control study or cohort study; $3)$ the publication that reported all data regarding the genotype of the CYP1A1 Ile462Val polymorphism that was required to calculate the odds ratio (OR) with a $95 \%$ confidence interval (CI); and 4) the study that used controls verified to have no clinical evidence of a malignancy. Accordingly, reviews and publications of overlapping studies were excluded. In the context of publications with overlapping data, those that included more data were preferentially used in the study. In total, 45 published studies evaluating the association between the CYP1A1 Ile462Val polymorphism and the risk of HNC were identified. We reviewed all the articles in accordance with the criteria defined earlier and excluded nine reviews and two publications with overlapping data. Ultimately, 34 studies were deemed to be eligible for the present study. One additional article ${ }^{45}$ was included in the oral cancer subgroup analysis only.

\section{Data extraction}

Data were extracted, analyzed by two investigators, and entered into an electronic database. The following information was collected from each study: author, year of publication, country, ethnicity, the source of control (hospital-based controls, which mean controls from hospital, and populationbased controls, which mean controls from randomly selected healthy individuals), study population size, genotype frequency, and tumor type. The key characteristics of the eligible studies are summarized in Table 1.

\section{Quantitative data synthesis}

A cumulative meta-analysis was performed to assess the association between the CYP1A1 Ile462Val polymorphism and the risk of HNC. ${ }^{46}$ The Cochrane $Q$ statistics test was used to examine heterogeneity. ${ }^{47}$ The data were combined using either a fixed-effects model or a random-effects model depending on the results of the heterogeneity test. The fixed-effects model was applied if no heterogeneity was detected. In all other cases, the random-effects model was applied. ${ }^{47} \mathrm{~A}$ funnel plot was created to assess publication bias. Begg's test (a linear regression approach used to measure funnel plot asymmetry on the natural logarithm scale of the OR $)^{48}$ was used to evaluate the symmetry of the funnel plot. A sensitivity analysis was conducted in which we sequentially removed each eligible study from the pooled data. ${ }^{46}$ The pooled OR of all the studies evaluated in this metaanalysis was calculated to evaluate the significance of the Ile/ Val+Val/Val vs the Ile/Ile genotype in HNC.

All the statistical analyses were conducted using the STATA 10.0 software package (StataCorp LP, College Station, TX, USA). All the tests were two-sided, and a $P$-value of $\leq 0.05$ was considered to be statistically significant.

\section{Results \\ Meta-analysis databases}

Table 1 lists some general information associated with the eligible studies, including the first author, year of publication, country, ethnicity of the patients, source of controls, tumor subtype, and study population size. We identified a total of 34 studies that included 6,367 cases and 6,395 controls that evaluated the association between the CYP1A1 Ile462Val polymorphism and the risk of HNC.

\section{Test of heterogeneity}

No heterogeneity was observed for the CYP1A1 Ile/Val+Val/ Val genotype vs the Ile/Ile genotype in the subgroup analyses of patients with pharyngeal cancer and Caucasian patients. Therefore, we calculated the pooled ORs for these two groups using the fixed-effects model. The random-effects model was used to calculate the pooled OR for the remaining subgroup analyses.

\section{Quantitative data synthesis}

Table 2 lists the pooled ORs associated with the CYP1A1 Ile462 Val polymorphism and the risk of HNC calculated 
Table I Characteristics of the selected studies

\begin{tabular}{|c|c|c|c|c|c|c|c|}
\hline First author & Year & Country & Ethnicity & $\begin{array}{l}\text { Source of } \\
\text { controls }\end{array}$ & Tumor type & Cases & Controls \\
\hline Park et al"I & 1997 & USA & Mixed & $\mathrm{HB}$ & Oral and laryngeal cancers & 131 & 131 \\
\hline Matthias et al ${ }^{12}$ & 1998 & Germany & Caucasian & $\mathrm{HB}$ & Oral, laryngeal, and pharyngeal cancers & 380 & 193 \\
\hline Oude Ophuis et al ${ }^{13}$ & 1998 & the Netherlands & Mixed & $\mathrm{HB}$ & Oral, laryngeal, and pharyngeal cancers & 185 & 207 \\
\hline Katoh et $\mathrm{al}^{14}$ & 1999 & Japan & Asian & $\mathrm{HB}$ & Oral cancer & 92 & 147 \\
\hline Morita et al ${ }^{15}$ & 1999 & Japan & Asian & $\mathrm{HB}$ & Oral, laryngeal, and pharyngeal cancers & 145 & 164 \\
\hline McWilliams et al ${ }^{16}$ & 2000 & USA & Caucasian & PB & Oral, laryngeal, and pharyngeal cancers & 139 & 121 \\
\hline Olshan et al ${ }^{17}$ & 2000 & USA & Mixed & $\mathrm{HB}$ & Oral, laryngeal, and pharyngeal cancers & 171 & 189 \\
\hline Sato et $\mathrm{al}^{18}$ & 2000 & Japan & Asian & PB & Oral cancer & 142 & 142 \\
\hline Ko et a $\left.\right|^{19}$ & 2001 & Germany & Caucasian & $\mathrm{HB}$ & Oral, laryngeal, and pharyngeal cancers & 312 & 300 \\
\hline Sreelekha et $\mathrm{a}^{20}$ & 2001 & India & Asian & $\mathrm{HB}$ & Oral cancer & 98 & 60 \\
\hline Hahn et $\mathrm{al}^{21}$ & 2002 & Germany & Caucasian & $\mathrm{HB}$ & Oral cancer & 94 & 92 \\
\hline Kao et $\mathrm{al}^{22}$ & 2002 & People's Republic of China & Asian & $\mathrm{HB}$ & Oral cancer & 106 & 146 \\
\hline Gronau et $\mathrm{al}^{23}$ & 2003 & Germany & Caucasian & $\mathrm{HB}$ & Oral, laryngeal, and pharyngeal cancers & 187 & 139 \\
\hline Gronau et $\mathrm{a}^{45, \mathrm{a}}$ & 2003 & Germany & Caucasian & $\mathrm{HB}$ & Oral cancer & 73 & 136 \\
\hline Varzim et $\mathrm{al}^{24}$ & 2003 & Portugal & Caucasian & $\mathrm{HB}$ & Laryngeal cancer & 88 & 177 \\
\hline Evans et $\mathrm{a}^{25}$ & 2004 & USA & Caucasian & PB & Oral, laryngeal, and pharyngeal cancers & 281 & 208 \\
\hline Li et $\mathrm{a}^{26}$ & 2004 & People's Republic of China & Asian & $\mathrm{HB}$ & Laryngeal cancer & 89 & 164 \\
\hline Xie et $\mathrm{al}^{27}$ & 2004 & USA & Mixed & PB & Oral cancer & 132 & 143 \\
\hline Gajecka et $\mathrm{al}^{28}$ & 2005 & Poland & Caucasian & $\mathrm{HB}$ & Laryngeal cancer & 289 & 316 \\
\hline Leichsenring et $\mathrm{al}^{29}$ & 2006 & Brazil & Mixed & PB & Oral cancer & 72 & 60 \\
\hline Marques et $\mathrm{al}^{30}$ & 2006 & Brazil & Mixed & $\mathrm{HB}$ & Oral cancer & 231 & 212 \\
\hline Sugimura et $\mathrm{a}^{31}$ & 2006 & Japan & Asian & $\mathrm{HB}$ & Oral cancer & 122 & 241 \\
\hline Reszka et $\mathrm{al}^{32}$ & 2008 & Poland & Caucasian & $\mathrm{HB}$ & Oral, laryngeal, and pharyngeal cancers & 127 & 145 \\
\hline Sam et $\mathrm{al}^{33}$ & 2008 & India & Asian & $\mathrm{HB}$ & Oral, laryngeal, and pharyngeal cancers & 408 & 220 \\
\hline Varela-Lema et $\mathrm{al}^{34}$ & 2008 & Spain & Caucasian & $\mathrm{HB}$ & Oral and pharyngeal cancers & 66 & 92 \\
\hline Amtha et $\mathrm{a}^{35}$ & 2009 & Indonesia & Asian & $\mathrm{HB}$ & Oral cancer & 81 & 162 \\
\hline Singh et $\mathrm{a}^{36}$ & 2009 & India & Asian & $\mathrm{HB}$ & Oral, laryngeal, and pharyngeal cancers & 200 & 200 \\
\hline Sabitha et $\mathrm{a}^{37}$ & 2010 & India & Asian & $\mathrm{HB}$ & Oral, laryngeal, and pharyngeal cancers & 205 & 245 \\
\hline Sharma et a ${ }^{38}$ & 2010 & India & Asian & $\mathrm{HB}$ & Oral, laryngeal, and pharyngeal cancers & 203 & 201 \\
\hline Tai et a ${ }^{39}$ & 2010 & People's Republic of China & Asian & $\mathrm{HB}$ & Laryngeal and pharyngeal cancers & 278 & 278 \\
\hline Lourenco et a $\left.\right|^{40}$ & 2011 & Brazil & Mixed & $\mathrm{HB}$ & Oral, laryngeal, and pharyngeal cancers & 142 & 142 \\
\hline Balaji et $\mathrm{a}^{41}$ & 2012 & India & Asian & $\mathrm{HB}$ & Oral cancer & 157 & 132 \\
\hline Szanyi et $\mathrm{a}^{42}$ & 2012 & Hungary & Caucasian & $\mathrm{HB}$ & Laryngeal and pharyngeal cancers & 142 & 150 \\
\hline Singh et al ${ }^{43}$ & 2014 & India & Asian & $\mathrm{HB}$ & Oral cancer & 122 & 127 \\
\hline Maurya et $\mathrm{al}^{44}$ & 2015 & India & Asian & Unknown & Oral, laryngeal, and pharyngeal cancers & 750 & 749 \\
\hline
\end{tabular}

Note: ancluded in the oral cancer subgroup analysis only.

Abbreviations: HB, hospital-based control study; PB, population-based control study.

Table 2 Pooled OR of the association between the CYPIAI lle462Val polymorphism and the risk of head and neck cancer

\begin{tabular}{|c|c|c|c|c|c|c|c|c|c|}
\hline \multirow[t]{2}{*}{ Group } & \multirow[t]{2}{*}{$\begin{array}{l}\text { Number of } \\
\text { studies }\end{array}$} & \multicolumn{2}{|c|}{$\begin{array}{l}\text { Heterogeneity } \\
\text { test }\end{array}$} & \multirow[t]{2}{*}{ Analysis model } & \multirow[t]{2}{*}{$\begin{array}{l}\text { Cumulative OR } \\
(95 \% \mathrm{Cl})\end{array}$} & \multicolumn{2}{|c|}{$\begin{array}{l}\text { Hypothesis } \\
\text { test }\end{array}$} & \multicolumn{2}{|c|}{ Begg's test } \\
\hline & & Q & $\boldsymbol{P}$ & & & $\mathbf{Z}$ & $P$ & $\mathbf{Z}$ & $P$ \\
\hline Overall & 34 & 104.34 & 0.000 & Random-effects model & $1.284(1.119-1.473)$ & 3.561 & 0.000 & 0.36 & 0.722 \\
\hline \multicolumn{10}{|l|}{ Tumor subtype } \\
\hline Oral cancer & 21 & 74.59 & 0.000 & Random-effects model & $1.181(0.930-1.500)$ & 1.364 & 0.173 & 0.23 & 0.820 \\
\hline Laryngeal cancer & 11 & 22.44 & 0.013 & Random-effects model & I.362 (1.102-1.685) & 2.854 & 0.004 & 0.78 & 0.436 \\
\hline Pharyngeal cancer & 7 & 6.82 & 0.338 & Fixed-effects model & $1.519(1.253-1.843)$ & 4.250 & 0.000 & 0.30 & 0.764 \\
\hline \multicolumn{10}{|l|}{ Ethnicity } \\
\hline Asians & 16 & 59.89 & 0.000 & Random-effects model & 1.371 (1.III-1.693) & 2.941 & 0.003 & 0.14 & 0.893 \\
\hline Caucasians & 11 & 14.98 & 0.135 & Fixed-effects model & $1.138(0.94 \mid-1.376)$ & 1.329 & 0.184 & 0.00 & 1.000 \\
\hline \multicolumn{10}{|l|}{ Source of controls } \\
\hline Population based & 5 & 14.08 & 0.007 & Random-effects model & $1.013(0.606-1.694)$ & 0.051 & 0.960 & 0.73 & 0.462 \\
\hline Hospital based & 28 & 80.64 & 0.000 & Random-effects model & $1.329(1.138-1.55 \mathrm{I})$ & 3.603 & 0.000 & 1.05 & 0.295 \\
\hline
\end{tabular}

Abbreviation: $O R$, odds ratio. 
for the 6,367 cases and 6,395 controls evaluated. Overall, we observed an increased risk of HNC in patients with the Ile/Val+Val/Val genotype compared to those with the Ile/Ile genotype, with a pooled OR of 1.284 (95\% CI: 1.119-1.473; Figure 1).

In the subgroup analyses of tumor types, we observed an increased risk of laryngeal cancer and pharyngeal cancer in patients with the Ile/Val+Val/Val genotype compared to those with the Ile/Ile genotype. The pooled ORs for laryngeal cancer and pharyngeal cancer were 1.362 (95\% CI: 1.102-1.685) and 1.519 (95\% CI: 1.253-1.843), respectively (Table 2 ). No significant association between the CYP1A1 Ile462Val polymorphism and the risk of oral cancer was observed. The pooled OR associated with the risk of oral cancer was 1.181 (95\% CI: 0.930-1.500; Table 2).

In the subgroup analyses of patients stratified by ethnicity, we observed an increased risk of HNC in Asians with the Ile/Val+Val/Val genotype compared to those with the Ile/Ile genotype, with a pooled OR of 1.371 (95\% CI: 1.111-1.693; Table 2). No significant association between the CYP1A1 Ile462Val polymorphism and the risk of HNC in Caucasians was observed. The pooled OR in this subgroup was 1.138 (95\% CI: 0.941-1.376; Table 2).
In the subgroup analysis in which the data were stratified according to the source of controls used in the study, we observed an increased risk of HNC associated with the Ile/Val+Val/Val genotype compared to those with the Ile/Ile genotype in patients from studies that used hospitalbased controls ( $\mathrm{OR}=1.329,95 \% \mathrm{CI}: 1.138-1.551$ ), but no significant association was observed in patients from studies that used population-based controls (OR $=1.013,95 \%$ CI: 0.606-1.694; Table 2).

\section{Bias diagnosis}

The publication bias was evaluated using a funnel plot analysis. The shape of the funnel plot appeared roughly symmetrical (Figure 2), and the results of Begg's test suggested that publication bias would not significantly affect the summary estimates.

\section{Sensitivity analysis}

To determine the impact of the individual data sets on the pooled OR, we conducted a sensitivity analysis in which each eligible study was consecutively omitted from the pooled data. The pooled OR was not significantly affected by the sequential deletion of individual studies, indicating that the results of this study are reliable and robust (Figure 3).

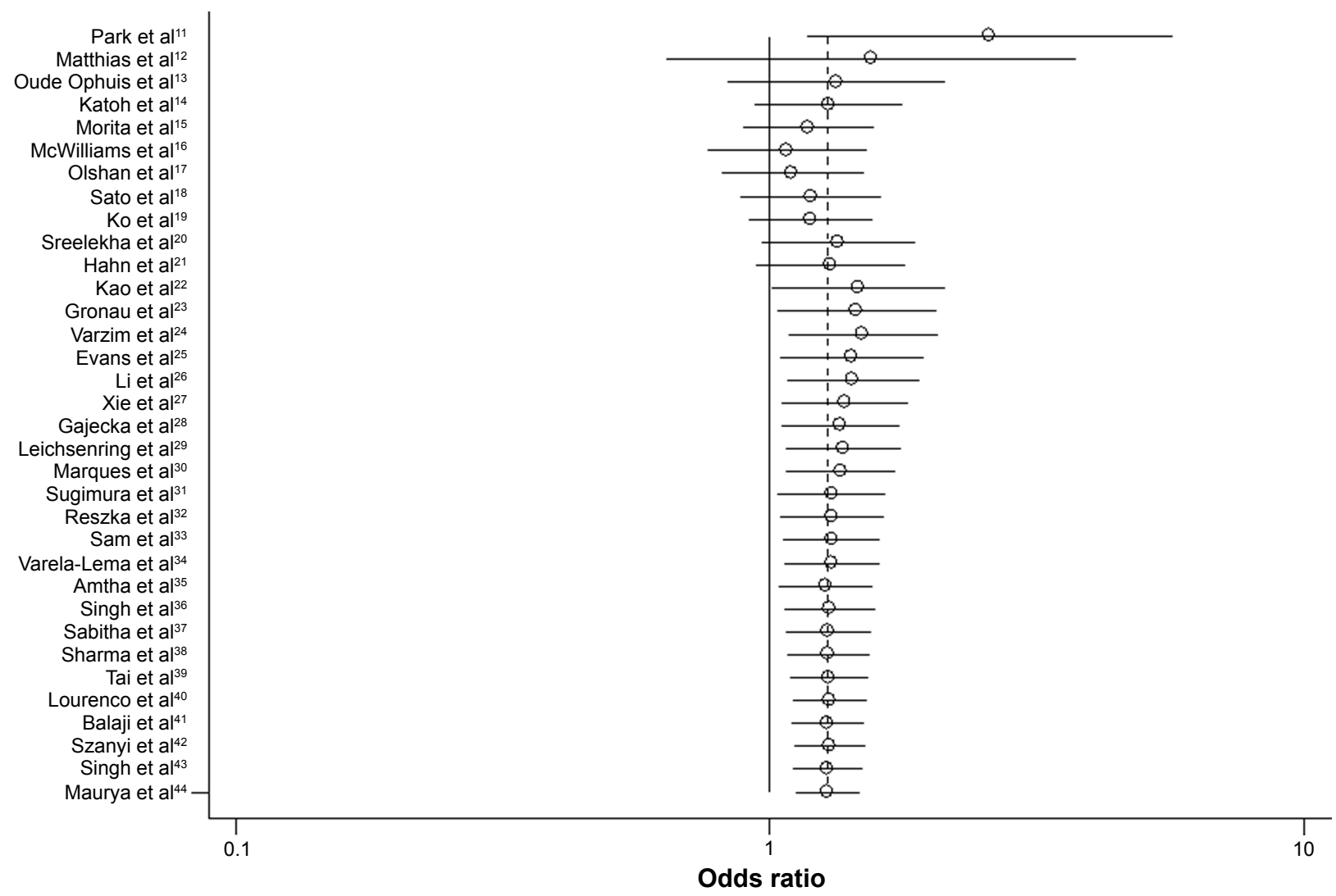

Figure I The cumulative meta-analysis of the association between the CYPIAI Ile462Val polymorphism and the risk of head and neck cancer (lle/Val+Val/Val vs Ile/lle). 


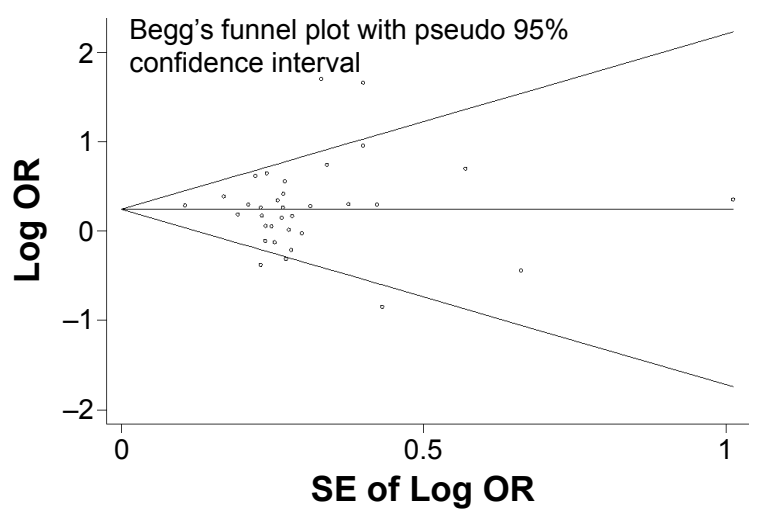

Figure 2 Funnel plot of the publication bias detected using Begg's test (lle/Val+Val/ $\mathrm{Val}$ vs lle/lle).

Notes: The $x$-axis represents the standard error of the log of the odds ratio, and the $y$-axis represents the log of the odds ratio.

Abbreviations: SE, standard error; OR, odds ratio.

\section{Discussion}

Although two previously published meta-analyses evaluated the association between the CYP1A1 Ile462Val polymorphism and the risk of $\mathrm{HNC},{ }^{49,50}$ careful examination of these data reveals several key issues worth noting. First,
Qin et al mistakenly included a study published by Cascorbi et $\mathrm{al}^{51}$ that evaluated the association between the $-463 \mathrm{G} / \mathrm{A}$ variant of the myeloperoxidase gene and the risk of cancer of the aerodigestive tract in their meta-analysis (supplemental Table 1 and supplemental references in the study of Qin et $\mathrm{al}^{50}$ ). Similarly, Qin et al also mistakenly included a study published by Bufalo et al ${ }^{52}$ that evaluated the association between the CYP1A1 Ile462Val polymorphism and the susceptibility of thyroid cancer in their metaanalysis (supplemental Table 1 and supplemental references in Qin et $\mathrm{al}^{50}$ ). Furthermore, Qin et $\mathrm{al}^{50}$ included one article with overlapping data. ${ }^{53}$

In the second meta-analysis, Liu et a ${ }^{49}$ reported data from a study by Katoh et al $^{14}$ that were inconsistent with the data reported by Katoh et al ${ }^{14}$ in their original publication. Katoh et al reported that they evaluated 92 cases and 147 controls (Table 3 in Katoh et $\mathrm{al}^{14}$ ); however, Liu et al reported that 147 cases and 92 controls had been evaluated in that study (Table 1 in Liu et $\mathrm{al}^{49}$ ). Similarly, Liu et al reported that Reszka et al's study evaluated 151 controls (Table 1 in Liu et $\left.\mathrm{al}^{49}\right)$, whereas Reszka et al reported that they evaluated

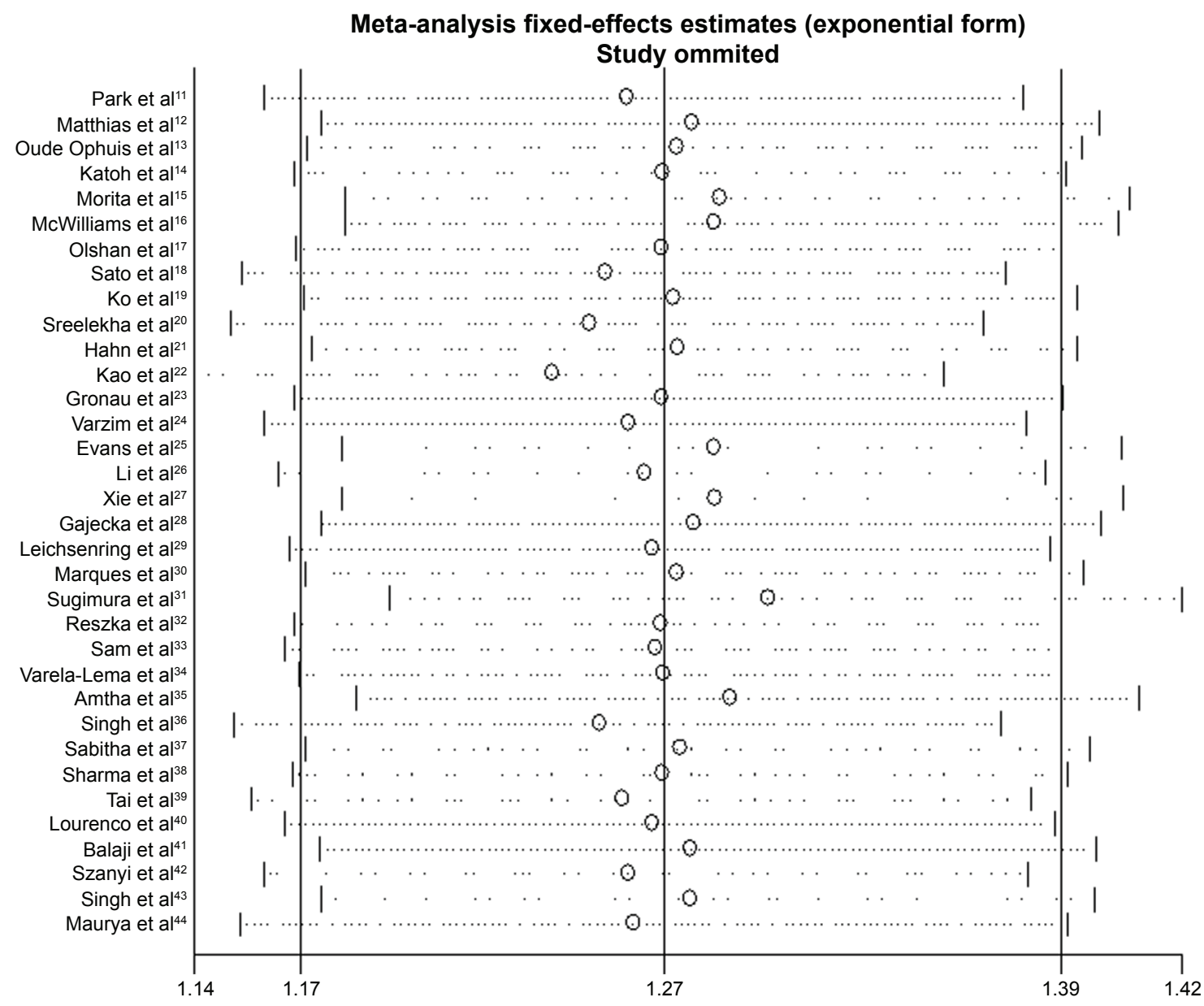

Figure 3 Sensitivity analysis of the association between the CYPIAI lle462Val polymorphism and the risk of head and neck cancer (lle/Val+Val/Val vs Ile/lle) 
145 controls (Table 2 in Reszka et al $^{32}$ ). Furthermore, Liu et al ${ }^{49}$ reported that the study by McWilliams et al ${ }^{16}$ evaluated 160 cases and 149 controls (Table 1 in Liu et $\mathrm{al}^{49}$ ). However, McWilliams et al reported that they evaluated 139 cases and 121 controls (Table 4 in McWilliams et $\mathrm{al}^{16}$ ). In addition, three eligible articles ${ }^{12,13,27}$ were not included in the study by Liu et al. ${ }^{49}$ Finally, although Sato et al reported that the CYP1A1 Ile462Val polymorphism was associated with an increased risk of oral cancer, ${ }^{18}$ these data were not included in the oral cancer subgroup analysis in the Liu et al's study (Figure 2A in Liu et $\mathrm{al}^{49}$ ).

Together, these observations indicate that current data describing the association between the CYP1A1 Ile462Val polymorphism and the risk of $\mathrm{HNC}$ are not entirely reliable. Three recent studies ${ }^{41,43,44}$ on this topic have been subsequently published; however, further verification of the association between the CYP1A1 Ile462Val polymorphism and the risk of $\mathrm{HNC}$ is still required. The cumulative metaanalysis reported here was conducted to verify the association of the CYP1A1 Ile462Val polymorphism with the risk of HNC using data from a total of 34 studies that evaluated 6,367 cases and 6,395 controls. The goal of this study was to provide comprehensive and conclusive evidence regarding the association of the CYP1A1 Ile462Val polymorphism with the risk of HNC. Overall, we observed an increased risk of $\mathrm{HNC}$ in patients with the Ile/Val+Val/Val genotype compared to those with the Ile/Ile genotype. We also observed an increased risk of HNC in patients with the Ile/Val+Val/ Val genotype compared to those with the Ile/Ile genotype in various subgroups (laryngeal cancer, pharyngeal cancer, Asians, and patients in studies that used hospital-based controls).

The potential limitations of this meta-analysis should also be acknowledged. First, only published articles were selected in this study; therefore, publication bias might have influenced the results. To address this issue, we evaluated the eligible studies using Begg's test and determined that the likelihood of publication bias was negligible. Second, although some confounding variables were well balanced between studies, different studies might have used different inclusion criteria and different sources of controls. These factors should be taken into account when interpreting the pooled data. To address this issue, we conducted subgroup analyses of patients in studies that used hospital-based controls and those that used population-based controls. Third, this cumulative meta-analysis is based on an unadjusted estimate; therefore, a more precise analysis accounting for adjusted factors should be carried out in the future.

\section{Conclusion}

Our results suggest that the $C Y P 1 A 1$ Ile462Val polymorphism is associated with an increased risk of HNC, particularly in laryngeal cancer and pharyngeal cancer. The verification of our findings requires additional well-designed studies evaluating large sample sizes.

\section{Acknowledgments}

This study was supported by grants from the National Natural Science Foundation of China (no U1404815) and the Henan Collaborative Innovation Center of Molecular Diagnosis and Laboratory Medicine (XTCX-2015-PY7). The funders had no role in the study design, data collection and analysis, decision to publish, or preparation of the article.

\section{Disclosure}

The authors report no conflicts of interest in this work.

\section{References}

1. Argiris A, Karamouzis MV, Raben D, Ferris RL. Head and neck cancer. Lancet. 2008;371(9625):1695-1709.

2. Hashibe M, Brennan $P$, Benhamou $S$, et al. Alcohol drinking in never users of tobacco, cigarette smoking in never drinkers, and the risk of head and neck cancer: pooled analysis in the International Head and Neck Cancer Epidemiology Consortium. J Natl Cancer Inst. 2007;99(10):777-789.

3. Network TCGA. Comprehensive genomic characterization of head and neck squamous cell carcinomas. Nature. 2015;517(7536):576-582.

4. Hayashi SI, Watanabe J, Nakachi K, Kawajiri K. PCR detection of an A/G polymorphism within exon 7 of the CYP1A1 gene. Nucleic Acids Res. 1991;19(17):4797.

5. Landi MT, Bertazzi PA, Shields PG, et al. Association between CYP1A1 genotype, mRNA expression and enzymatic activity in humans. Pharmacogenetics. 1994;4(5):242-246.

6. Han G, Ma Y, Liu P, Wei X, Zhang X, Zhu F. Quantitative synthesis of the association between the cytochrome P450 1A1 Ile462Val polymorphism and prostate cancer risk. Tumour Biol. 2013;34(3):1511-1516.

7. Gong FF, Lu SS, Hu CY, et al. Cytochrome P450 1A1 (CYP1A1) polymorphism and susceptibility to esophageal cancer: an updated meta-analysis of 27 studies. Tumour Biol. 2014;35(10):10351-10361.

8. Wei XP, Hu J. Cytochrome P450 1A1 exon 7 polymorphism and susceptibility to lung cancer in the Chinese population: an updated meta-analysis and review. Onco Targets Ther. 2015;8:1611-1618.

9. Yang S, Jia C, Zhu H, Han S. CYP1A1 Ile462Val polymorphism and cervical cancer: evidence from a meta-analysis. Tumour Biol. 2012;33(6): 2265-2272.

10. Lu J, Zhao Q, Zhai YJ, et al. Genetic polymorphisms of CYP1A1 and risk of leukemia: a meta-analysis. Onco Targets Ther. 2015;8:2883-2902.

11. Park JY, Muscat JE, Ren Q, et al. CYP1A1 and GSTM1 polymorphisms and oral cancer risk. Cancer Epidemiol Biomarkers Prev. 1997;6(10): 791-797.

12. Matthias $C$, Bockmuhl U, Jahnke V, et al. Polymorphism in cytochrome P450 CYP2D6, CYP1A1, CYP2E1 and glutathione S-transferase, GSTM1, GSTM3, GSTT1 and susceptibility to tobacco-related cancers: studies in upper aerodigestive tract cancers. Pharmacogenetics. 1998; 8(2):91-100.

13. Oude Ophuis MB, van Lieshout EM, Roelofs HM, Peters WH, Manni JJ. Glutathione S-transferase M1 and T1 and cytochrome P4501A1 polymorphisms in relation to the risk for benign and malignant head and neck lesions. Cancer. 1998;82(5):936-943. 
14. Katoh T, Kaneko S, Kohshi K, et al. Genetic polymorphisms of tobaccoand alcohol-related metabolizing enzymes and oral cavity cancer. Int J Cancer. 1999;83(5):606-609.

15. Morita S, Yano M, Tsujinaka T, et al. Genetic polymorphisms of drugmetabolizing enzymes and susceptibility to head-and-neck squamouscell carcinoma. Int J Cancer. 1999;80(5):685-688.

16. McWilliams JE, Evans AJ, Beer TM, et al. Genetic polymorphisms in head and neck cancer risk. Head Neck. 2000;22(6):609-617.

17. Olshan AF, Weissler MC, Watson MA, Bell DA. GSTM1, GSTT1, GSTP1, CYP1A1, and NAT1 polymorphisms, tobacco use, and the risk of head and neck cancer. Cancer Epidemiol Biomarkers Prev. 2000; 9(2):185-191.

18. Sato M, Sato T, Izumo T, Amagasa T. Genetically high susceptibility to oral squamous cell carcinoma in terms of combined genotyping of CYP1A1 and GSTM1 genes. Oral Oncol. 2000;36(3):267-271.

19. Ko Y, Abel J, Harth V, et al. Association of CYP1B1 codon 432 mutant allele in head and neck squamous cell cancer is reflected by somatic mutations of p53 in tumor tissue. Cancer Res. 2001;61(11):4398-4404.

20. Sreelekha TT, Ramadas K, Pandey M, Thomas G, Nalinakumari KR, Pillai MR. Genetic polymorphism of CYP1A1, GSTM1 and GSTT1 genes in Indian oral cancer. Oral Oncol. 2001;37(7):593-598.

21. Hahn M, Hagedorn G, Kuhlisch E, Schackert HK, Eckelt U. Genetic polymorphisms of drug-metabolizing enzymes and susceptibility to oral cavity cancer. Oral Oncol. 2002;38(5):486-490.

22. Kao SY, Wu CH, Lin SC, et al. Genetic polymorphism of cytochrome P4501A1 and susceptibility to oral squamous cell carcinoma and oral precancer lesions associated with smoking/betel use. J Oral Pathol Med. 2002;31(9):505-511.

23. Gronau S, Koenig-Greger D, Jerg M, Riechelmann H. Gene polymorphisms in detoxification enzymes as susceptibility factor for head and neck cancer? Otolaryngol Head Neck Surg. 2003;128(5):674-680.

24. Varzim G, Monteiro E, Silva RA, Fernandes J, Lopes C. CYP1A1 and $\mathrm{XRCC} 1$ gene polymorphisms in SCC of the larynx. Eur J Cancer Prev. 2003;12(6):495-499.

25. Evans AJ, Henner WD, Eilers KM, et al. Polymorphisms of GSTT1 and related genes in head and neck cancer risk. Head Neck. 2004; 26(1):63-70.

26. Li L, Lin P, Deng YF, Zhu ZL, Lu HH. Relationship between susceptibility and prognosis of laryngeal cancer and genetic polymorphisms in CYP1A1 and GSTM1. Zhonghua Er Bi Yan Hou Ke Za Zhi. 2004; 39(1):2-7.

27. Xie H, Hou L, Shields PG, et al. Metabolic polymorphisms, smoking, and oral cancer in Puerto Rico. Oncol Res. 2004;14(6):315-320.

28. Gajecka M, Rydzanicz M, Jaskula-Sztul R, Kujawski M, Szyfter W, Szyfter K. CYP1A1, CYP2D6, CYP2E1, NAT2, GSTM1 and GSTT1 polymorphisms or their combinations are associated with the increased risk of the laryngeal squamous cell carcinoma. Mutat Res. 2005; 574(1-2):112-123.

29. Leichsenring A, Losi-Guembarovski R, Maciel ME, et al. CYP1A1 and GSTP1 polymorphisms in an oral cancer case-control study. Braz J Med Biol Res. 2006;39(12):1569-1574.

30. Marques CF, Koifman S, Koifman RJ, Boffetta P, Brennan P, Hatagima A. Influence of CYP1A1, CYP2E1, GSTM3 and NAT2 genetic polymorphisms in oral cancer susceptibility: results from a case-control study in Rio de Janeiro. Oral Oncol. 2006;42(6):632-637.

31. Sugimura T, Kumimoto H, Tohnai I, et al. Gene-environment interaction involved in oral carcinogenesis: molecular epidemiological study for metabolic and DNA repair gene polymorphisms. J Oral Pathol Med. 2006;35(1):11-18

32. Reszka E, Czekaj P, Adamska J, Wasowicz W. Relevance of glutathione S-transferase M1 and cytochrome P450 1A1 genetic polymorphisms to the development of head and neck cancers. Clin Chem Lab Med. 2008;46(8):1090-1096.

33. Sam SS, Thomas V, Reddy SK, Surianarayanan G, Chandrasekaran A CYP1A1 polymorphisms and the risk of upper aerodigestive tract cancers in an Indian population. Head Neck. 2008;30(12):1566-1574.
34. Varela-Lema L, Ruano-Ravina A, Juiz Crespo MA, Kelsey KT, Loidi L, Barros-Dios JM. CYP1A1, mEH, and GSTM1 polymophisms and risk of oral and pharyngeal cancer: a Spanish Case-Control Study. J Oncol. 2008;2008:741310.

35. Amtha R, Ching CS, Zain R, et al. GSTM1, GSTT1 and CYP1A1 polymorphisms and risk of oral cancer: a case-control study in Jakarta, Indonesia. Asian Pac J Cancer Prev. 2009;10(1):21-26.

36. Singh AP, Shah PP, Ruwali M, Mathur N, Pant MC, Parmar D. Polymorphism in cytochrome P4501A1 is significantly associated with head and neck cancer risk. Cancer Invest. 2009;27(8):869-876.

37. Sabitha K, Reddy MV, Jamil K. Smoking related risk involved in individuals carrying genetic variants of CYP1A1 gene in head and neck cancer. Cancer Epidemiol. 2010;34(5):587-592.

38. Sharma R, Ahuja M, Panda NK, Khullar M. Combined effect of smoking and polymorphisms in tobacco carcinogen-metabolizing enzymes CYP1A1 and GSTM1 on the head and neck cancer risk in North Indians. DNA Cell Biol. 2010;29(8):441-448.

39. Tai J, Yang M, Ni X, et al. Genetic polymorphisms in cytochrome P450 genes are associated with an increased risk of squamous cell carcinoma of the larynx and hypopharynx in a Chinese population. Cancer Genet Cytogenet. 2010;196(1):76-82.

40. Lourenco GJ, Silva EF, Rinck-Junior JA, Chone CT, Lima CS. CYP1A1, GSTM1 and GSTT1 polymorphisms, tobacco and alcohol status and risk of head and neck squamous cell carcinoma. Tumour Biol. 2011;32(6):1209-1215.

41. Balaji L, Singh KB, Bhaskar LV. CYP1A1 genotypes and haplotypes and risk of oral cancer: a case-control study in South Indians. Genet Mol Biol. 2012;35(2):407-412.

42. Szanyi I, Rath G, Moricz P, et al. Effects of cytochrome P450 1A1 and uridine-diphosphate-glucuronosyltransferase 1A1 allelic polymorphisms on the risk of development and the prognosis of head and neck cancers. Eur J Cancer Prev. 2012;21(6):560-568.

43. Singh RD, Haridas N, Shah FD, Patel JB, Shukla SN, Patel PS. Gene polymorphisms, tobacco exposure and oral cancer susceptibility: a study from Gujarat, West India. Oral Dis. 2014;20(1):84-93.

44. Maurya SS, Katiyar T, Dhawan A, et al. Gene-environment interactions in determining differences in genetic susceptibility to cancer in subsites of the head and neck. Environ Mol Mutagen. 2015;56(3):313-321.

45. Gronau S, Koenig-Greger D, Jerg M, Riechelmann H. GSTM1 enzyme concentration and enzyme activity in correlation to the genotype of detoxification enzymes in squamous cell carcinoma of the oral cavity. Oral Dis. 2003;9(2):62-67.

46. Wang Y, Yang H, Wang H. The association of GSTT1 deletion polymorphism with lung cancer risk among Chinese population: evidence based on a cumulative meta-analysis. Onco Targets Ther. 2015;8: 2875-2882.

47. DerSimonian R, Laird N. Meta-analysis in clinical trials. Control Clin Trials. 1986;7(3):177-188.

48. Begg CB, Mazumdar M. Operating characteristics of a rank correlation test for publication bias. Biometrics. 1994;50(4):1088-1101.

49. Liu L, Wu G, Xue F, et al. Functional CYP1A1 genetic variants, alone and in combination with smoking, contribute to development of head and neck cancers. Eur J Cancer. 2013;49(9):2143-2151.

50. Qin J, Zhang JX, Li XP, Wu BQ, Chen GB, He XF. Association between the CYP1A1 A2455G polymorphism and risk of cancer: evidence from 272 case-control studies. Tumour Biol. 2014;35(4):3363-3376.

51. Cascorbi I, Henning S, Brockmoller J, et al. Substantially reduced risk of cancer of the aerodigestive tract in subjects with variant $-463 \mathrm{~A}$ of the myeloperoxidase gene. Cancer Res. 2000;60(3):644-649.

52. Bufalo NE, Leite JL, Guilhen AC, et al. Smoking and susceptibility to thyroid cancer: an inverse association with CYP1A1 allelic variants. Endocr Relat Cancer. 2006;13(4):1185-1193.

53. Katoh T. Application of molecular biology to occupational health field - the frequency of gene polymorphism of cytochrome P450 1A1 and glutathione S-transferase M1 in patients with lung, oral and urothelial cancer. J UOEH. 1995;17(4):271-278. 


\section{Publish your work in this journal}

OncoTargets and Therapy is an international, peer-reviewed, open access journal focusing on the pathological basis of all cancers, potential targets for therapy and treatment protocols employed to improve the management of cancer patients. The journal also focuses on the impact of management programs and new therapeutic agents and protocols on

patient perspectives such as quality of life, adherence and satisfaction. The manuscript management system is completely online and includes a very quick and fair peer-review system, which is all easy to use. Visit http://www.dovepress.com/testimonials.php to read real quotes from published authors.

Submit your manuscript here: http://www.dovepress.com/oncotargets-and-therapy-journal 